IMPACT OF TARGET MATERIAL ACTIVATION ON PERSONNEL EXPOSURE AND RADIOACTIVE CONTAMINATION IN THE NATIONAL IGNITION FACILITY

H. Khater, P. Epperson, R. Thacker, R. Beale, T. Kohut, S. Brereton

July 13, 2009

IEEE Transactions on Plasma Science 
This document was prepared as an account of work sponsored by an agency of the United States government. Neither the United States government nor Lawrence Livermore National Security, LLC, nor any of their employees makes any warranty, expressed or implied, or assumes any legal liability or responsibility for the accuracy, completeness, or usefulness of any information, apparatus, product, or process disclosed, or represents that its use would not infringe privately owned rights. Reference herein to any specific commercial product, process, or service by trade name, trademark, manufacturer, or otherwise does not necessarily constitute or imply its endorsement, recommendation, or favoring by the United States government or Lawrence Livermore National Security, LLC. The views and opinions of authors expressed herein do not necessarily state or reflect those of the United States government or Lawrence Livermore National Security, LLC, and shall not be used for advertising or product endorsement purposes. 


\title{
Title: IMPACT OF TARGET MATERIAL ACTIVATION ON PERSONNEL EXPOSURE AND RADIOACTIVE CONTAMINATION IN THE NATIONAL IGNITION FACILITY
}

\author{
Authors: Hesham Khater, Patrick Epperson, Rick Thacker, Richard Beale, Tom Kohut, \\ and Sandra Brereton \\ Lawrence Livermore National Laboratory \\ P. O. Box 808 , L-462 \\ Livermore, CA 94550
}

Corresponding Author: Hesham Khater

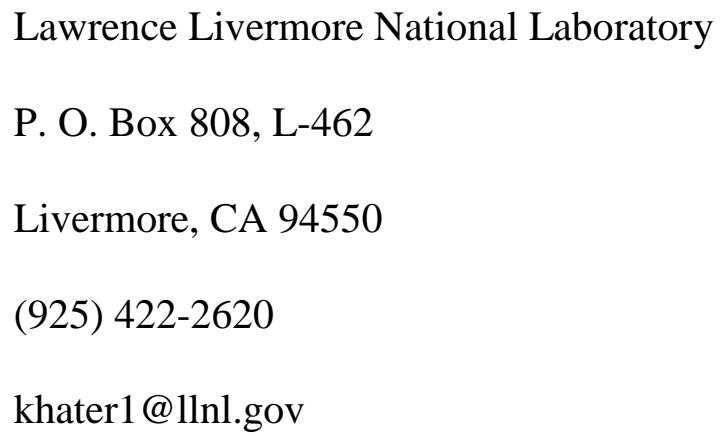

Number of Pages: $\quad 22$

Number of Figures: 5

Number of Tables: 2 


\section{ABSTRACT}

Detailed activation analyses are performed for the different materials under consideration for use in the target capsules and hohlraums used during the ignition campaign on the National Ignition Facility. Results of the target material activation were additionally used to estimate the levels of contamination within the NIF target chamber and the workplace controls necessary for safe operation. The analysis examined the impact of using $\mathrm{Be}-\mathrm{Cu}$ and $\mathrm{Ge}$-doped $\mathrm{CH}$ capsules on the external dose received by workers during maintenance activities. Five days following a $20 \mathrm{MJ}$ shot, dose rates inside the Target Chamber (TC) due to the two proposed capsule materials are small ( 1 $\mu \mathrm{rem} / \mathrm{h}$ ). Gold and depleted-uranium (DU) are considered as potential hohlraum materials. Following a shot, gold will most probably get deposited on the TC first wall. On the other hand, while noble-gas precursors from the DU are expected to stay in the TC, most of the noble gases are pumped out of the chamber and end up on the cryopumps. The dose rates inside the TC due to activated gold or DU, at 5 days following a $20 \mathrm{MJ}$ shot, are about $1 \mathrm{mrem} / \mathrm{h}$. Dose rates in the vicinity of the cryo-pumps (containing noble "fission" gases) drop-off to about $1 \mathrm{mrem} / \mathrm{h}$ during the first 12 hours following the shot. Contamination from activation of NIF targets will result in the NIF target chamber exceeding DOE surface contamination limits. Objects removed from the TC will need to be managed as radioactive material. However, the results suggest that airborne contamination from resuspension of surface contamination will not be significant and is at levels that can be managed by negative ventilation when accessing the TC attachments. 


\section{INTRODUCTION}

The National Ignition Facility (NIF) at Lawrence Livermore National Laboratory is the world's largest and most energetic laser system for inertial confinement fusion. NIF is a 192 laser beam facility that will produce $1.8 \mathrm{MJ}, 500 \mathrm{TW}$ of ultraviolet light. Laser beam interaction with the target hohlraum and the resulting burning of the target fuel will result in the generation of neutrons and the resulting activation of hohlraum materials by the neutron flux. During the ignition campaign, Deuterium-Tritium (D-T) shots will routinely generate $20 \mathrm{MJ}$ of yield, with a maximum annual yield of $1200 \mathrm{MJ}$. This paper only focuses on activation of target material during the ignition campaign.

Fig. 1 shows the current point design for an ignition target. Half of the laser beams enter through each of the two Laser Entrance Holes (LEH). The heated inner hohlraum wall emits x-rays which drive the implosion of the capsule surrounding the fuel. Neutrons generated as a result of the fuel burn will activate the capsule and hohlraum materials. The vaporized hohlraum materials will be deposited on the inner surface of the Target Chamber (TC) first wall. In this paper, an assessment of the impact the target material activation will have on personnel exposure and radioactive contamination is presented.

A variety of target materials are considered for use during the National Ignition Campaign (NIC). This paper focuses on analyzing the few capsule and hohlraum materials that are part of the current NIF shot plan. Targets fabricated by General Atomics consist of a fuel capsule that is about $150 \mu \mathrm{m}$-thick and with an inner diameter of $1040 \mu \mathrm{m}$. Two types of capsules are considered. The first type is made of a highquality beryllium alloy that contains about 0.35 at $\%$ copper. The second option is to use a 
hydrocarbon $(\mathrm{CH})$ that is doped with germanium also at about 0.35 at\%. Surrounding the capsule is a hohlraum in the shape of a cylinder with an inner wall measuring about $5 \mathrm{~mm}$ diameter and $9 \mathrm{~mm}$ high. The three types of ignition hohlraums considered are made of gold $(\mathrm{Au})$, depleted uranium (DU), or a mixture of depleted uranium and gold (75\% DU and $25 \% \mathrm{Au}$ ). The inner surface of this $10 \mu \mathrm{m}$-thick hohlraum is covered with a $0.2 \mu \mathrm{m}$ thick liner made of gold or a mixture of gold and boron (80\% Au and 20\% B). The hohlraum is surrounded with a $42 \mu \mathrm{m}$-thick layer of gold to prevent oxidation and provide structural support. The hohlraum and the gold support are enclosed in a $150 \mu \mathrm{m}$ thick aluminum can made of Al-5052 alloy. Finally two silicon cooling arms surround the aluminum can.

\section{Evaluation of Personnel exposure}

A detailed neutron transport calculation and activation analysis were used to evaluation personnel exposure due to activated target materials. A three-Dimensional model of the hohlraum has been developed using the MCNP5 radiation transport code [1]. The hohlraum is placed in a detailed model of the Target Chamber. The TC is a sphere with an inner radius of $5 \mathrm{~m}$ and a 10 -cm-thick wall made of the low activation aluminum alloy (Al 5083). The chamber wall is covered on the inside by steel panels made of the low activation stainless-steel 409 alloy. In addition, the TC is surrounded on the outside by $40-\mathrm{cm}$ of borated concrete, which acts as a neutron shield. The neutron transport calculations utilized neutron cross section data from the FENDL-2.1 cross section database [2]. Neutron fluxes were calculated for all materials considered for the 
proposed ignition target. These fluxes were then used to calculate the level of radioactivity induced in each material following one shot as well as at the end of one year of operation. One year of operation was modeled as sixty $20 \mathrm{MJ}$ shots with 6.18 days in between shots. The 175-group FENDL/A-2.0 activation cross-section library [3] along with the FENDL/D-2.0 decay data library were used by the activation code ALARA [4] to calculate the radioactive inventory and decay gamma source for all materials except for DU. The $14 \mathrm{MeV}$ neutrons will induce fission reactions in the uranium atoms, resulting in the generation of a large number of fission products. Activation of DU was also performed by ALARA by using the CINDER'90 63-group neutron data library [5]. The calculated decay gamma sources were finally transported by MCNP5 to calculate the effective dose at selected locations inside and outside the TC and as a function of time following shots. The effective dose values were calculated by using ICRP-74 AnteriorPosterior (AP) neutron fluence-to-dose conversion coefficients [6].

Radiation dose rates are the highest inside the Target Chamber. Following a shot, the activated target materials are expected to be uniformly deposited on the surface of the first wall steel panels. As such, one would expect that any maintenance activities inside the TC would include exposure to gamma decay from the activated target materials. It is important to note that the overall personnel exposure during maintenance activities inside the TC is dominated by decay from the activated first wall steel panels, aluminum chamber and gunite shield. Dose due activation of to target materials is a small addition to the overall dose inside the TC. A second potential for exposure occurs outside the TC and is caused by fission gases resulting from the decay of the DU fission products. 
Following a shot it is assumed that all activated target materials and their decay daughters stay in the chamber and do not escape. This is not true for noble gases, which will most probably escape to the cryo-pumps outside the chamber.

\section{II.a. Dose inside the Target Chamber}

Dose rates were calculated for potential maintenance activities under the assumption that the maintenances tasks would be performed at a distance of 1 ' from the first wall panels (FW). Fig. 2 shows the dose rates expected due to activated capsules materials considered in this analysis. The hazard inside the TC due to activated capsules is very small with Be capsules producing a higher dose than $\mathrm{CH}$ during the first day. The dose rate due to activation of a Be capsule drops to $1 \mathrm{mrem} / \mathrm{h}$ after one hour. The Be capsule dose is dominated by contributions from $\mathrm{Cu}$ isotopes, ${ }^{62} \mathrm{Cu}$ and ${ }^{66} \mathrm{Cu}$. The $\mathrm{CH}$ capsule dose rate drops to a similar level within 10 minutes. In this case, the dose is dominated by ${ }^{74} \mathrm{Ga}$ during the first hour, and ${ }^{72} \mathrm{Ga}$ and ${ }^{69} \mathrm{Ge}$ during the first day. In short, capsule activation is dominated by activation of added material/dopant.

A comparison between the potential hohlraum materials is shown in Fig. 3. After one week, the dose rate due to activation of the $10 \mu \mathrm{m}$ DU hohlraum wall drops to $1 \mathrm{mrem} / \mathrm{h}$. The DU dose is dominated by contribution from the fission products. Isotopes like ${ }^{88} \mathrm{Ga}$, ${ }^{92} \mathrm{Sr}$ and ${ }^{142} \mathrm{La}$ dominate during the first hour. At one day the DU dose is dominated by isotopes like ${ }^{132} \mathrm{I},{ }^{135} \mathrm{I}$ and ${ }^{91} \mathrm{Sr}$. The Au dose is caused by the decay of ${ }^{197 \mathrm{~m}} \mathrm{Au}$ during the first minute with ${ }^{196} \mathrm{Au}$ responsible for dose beyond the first minute. A DU hohlraum continues to generate higher dose rates than the gold hohlraum for up to a week following the shot. Due to the long dwell time between the shots, dose rates are almost entirely 
dominated by the last target shot. Target materials from previous shots will decay out between the shots while being exposed to about 6 orders of magnitude lower flux after being deposited on the first wall panels (i.e., very little amount of additional activation is added to the previously activated target materials after being deposited on the first wall).

As mentioned before, the hohlraum is surrounded by a $42 \mu \mathrm{m}$-thick layer of gold and both are enclosed in a $150 \mu \mathrm{m}$-thick aluminum can made of Al-5052 alloy with two silicon cooling arms surrounding the aluminum can. A comparison between these components shows that both the aluminum can and the DU hohlraum generate equivalent levels of dose rates during the first few hours. As shown in Fig. 4, the very short-lived ${ }^{24 m} \mathrm{Na}$ generates a high dose rate from the aluminum can during the first few seconds. A higher dose contribution from the can is also shown during the first 3 days, a period of time during which ${ }^{24} \mathrm{Na}$ is the dominant isotope. The dose rate due to the $42 \mu \mathrm{m}$ layer of gold exceeds the DU dose within 12 hours.

\section{II.b. Dose outside the Target Chamber}

Fission products are generated from the DU hohlraums. Following a shot, it is fair to assume that most of the fission products will stay inside the Target Chamber and hence limit the radiological exposure to inside the TC. Nevertheless, even though noble gas precursors will stay inside the chamber, noble gases like krypton and xenon will most probably leave the chamber and end-up accumulating on the cryo-pumps. This could pose a potential source of dose during maintenance activities in the vicinity of the cryopumps. Fig. 5 shows the expected dose rates outside the cryo-pump as a function of distance following a $20 \mathrm{MJ}$ shot. Dose rates in the figure assume that the entire inventory 
of activated noble gases is transported outside the TC. ${ }^{87} \mathrm{Kr},{ }^{88} \mathrm{Kr}$ and ${ }^{138} \mathrm{Xe}$ are responsible for most of the dose during the first few hours following the shot. Within a day, the dose rate at a distance of 1' drops below $1 \mathrm{mrem} / \mathrm{h}$.

\section{RADIOACTIVE CONTAMINATION MODEL}

Results of the target material activation from a single target and $20 \mathrm{MJ}$ yield were used to estimate the levels of contamination within the NIF target chamber and the workplace controls necessary for safe operation. The build up and decay of activation products is based on the NIF program shot plan of March 2009 which projects shot dates and theoretical yields in 2010 to 2012 . The contamination model presented here focused on analyzing targets with DU hohlraum, which are the most challenging from contamination point of view. The model also assumes that the generation of activation products was linear with yield and the activated debris products are uniformly distributed across the chamber surface. A conservative assumption was made to ignore cleaning of the target chamber and allow for contamination builds up. Over 1400 isotopes were generated as a result of the activation analysis. A decision was made to reduce the set of isotopes tracked to those that are significant from a contamination standpoint. Radioactive isotopes were sorted by their level of activity one day after a shot and normalized by the derived air concentration (DAC) values in appendix D of 10CFR835 [7] to account for the relative dose effect of different isotopes. Table I lists the set of isotopes that contribute $99 \%$ of the hazard, assuming access to NIF target chamber attachments within 1 to 10 days after the last shot. 
Estimates of contamination levels were used to evaluate impact to operations for control of contaminated material, worker respiratory protection, workplace type and ventilation, and continuous air monitoring as summarized in Table II. Gross surface contamination results in $\mathrm{Bq} / \mathrm{cm}^{2}$ in Table II represent the buildup of contamination over the three years for all isotopes. Removable surface contamination limits in Appendix D of 10CFR835 $\left(10 \mathrm{~Bq} / \mathrm{cm}^{2}\right.$ for most beta/gamma emitters and uranium, $0.2 \mathrm{~Bq} / \mathrm{cm}^{2}$ for most alpha emitting isotopes) were used to evaluate if material in the target chamber can be released from radiological controls. The surface contamination level for each of the 37 isotopes was compared against its Appendix D value and the sum of the ratios were calculated. The results show that target chamber objects will be contaminated at levels above the release limits for surface contamination and therefore must be controlled as radioactively contaminated or be decontaminated prior to uncontrolled release. The fraction of surface contamination that becomes airborne during routine access of the target chamber can be estimated using a resuspension factor defined as:

$$
\mathrm{f}_{\mathrm{r}}=\frac{\text { atmospheric concentration } \mathrm{Bq} / \mathrm{m}^{3}}{\text { surface contamination } \mathrm{Bq} / \mathrm{m}^{2}}
$$

Resuspension factors for indoor operations typically range from $10^{-3}$ to $10^{-8} \mathrm{~m}^{-1}$ depending on the surface and work conditions [8]. A conservative re-suspension factor of $10^{-4} \mathrm{~m}^{-1}$ which assumes dry/mobilizable deposits and "disturbing" type activities, which is conservative for the expected NIF operations was adopted. For operations that involve opening the target chamber the model estimates gross airborne activity concentrations ranging from 200 to $2000 \mathrm{~Bq} / \mathrm{m}^{3}$. The airborne concentration for each isotope was compared to the DAC values in 10CFR835 and the sum of the ratios for each year is 
listed in Table II as the fraction of the DAC. The results show that airborne contamination levels for all years are less than a single DAC and suggest that NIF is not expected to have significant airborne contamination levels from target fission and activation products.

In general, operations that involve opening the target chamber attachments will be done with ventilation/air flow into the target chamber attachment. In order to evaluate that this level of protection (i.e., hood-like environment) is sufficient for the contamination level in the target chamber, a health physics modeling code, HotSpot [9] was used. For a given isotopic mixture and operating conditions, the program recommends whether material should be handled in a glovebox (Type 3 workplace) or a ventilated enclosure, such as a fume hood (Type 2 workplace). The results in Table II show that contamination levels will be a small fraction of the threshold for a Type 3 workplace and that a ventilated workspace is appropriate. Overall, the results of the airborne contamination and workplace type evaluations suggest that respiratory protection for operations involving access to the target chamber attachments is not required. In practice, respiratory protection will be used until actual surface and airborne contamination levels are well characterized and understood.

Finally, 10CFR835.403 requires continuous monitoring for airborne contamination whenever an individual is likely to receive an exposure of 40 or more DAC-hour in a year. The total contamination levels at the end of 2012 and LLNL procedure HP-FO-04 [10] which considers release, confinement and dispersion factors for the NIF environment were used to calculate the intake for operations. The estimated annual intake for NIF 
operations using 2012 contamination levels is $8.8 \times 10^{-2}$ DAC hour, well below the 40 DAC hour threshold; therefore continuous air monitoring is not required.

\section{CONCLUSIONS}

Detailed activation analysis and dose rate calculations are performed for the different target materials under consideration for use at the National Ignition Facility. The use of Be-Cu or Ge-doped $\mathrm{CH}$ capsules results in small external dose rates. Gold and depleteduranium are considered as potential hohlraum materials. The dose rate due to activation of a $10 \mu \mathrm{m}$ DU hohlraum wall drops to $1 \mathrm{mrem} / \mathrm{h}$ after one week. A DU hohlraum continues to generate higher dose rates than the gold hohlraum for up to a week following a $20 \mathrm{MJ}$ shot. Contamination from activation of NIF targets will result in the NIF target chamber exceeding DOE surface contamination limits. Objects removed from the target chamber will need to be managed as radioactive material. However, the results suggest that airborne contamination from resuspension of surface contamination will not be significant and is at levels that can be managed by negative ventilation when accessing the target chamber attachments.

\section{ACKNOWLEDGMENTS}

This work performed under the auspices of the U.S. Department of Energy by Lawrence Livermore National Laboratory under Contract DE-AC52-07NA27344. 


\section{REFERENCES}

[1] X-5 Monte Carlo Team, "MCNP - A General Monte Carlo N-Particle Transport Code, Version 5,” Los Alamos National Laboratory, LA-UR-03-1987, 2005.

[2] D. L. Aldama and A.Trkov, "FENDL-2.1: Evaluated Nuclear Data Library for Fusion Applications,” International Atomic Energy Agency, INDC(NDS)-467, 2004.

[3] A. Pashchenko et al., "FENDL/A-2.0: Neutron Activation Cross-Section Data Library for Fusion Applications,” Report INDC (NDS)-173, IAEA Nuclear Data Section, March 1997.

[4] P. Wilson and D. Henderson, "ALARA: Analytic and Laplacian Adaptive Radioactivity Analysis code," University of Wisconsin, UWFDM-1070, 1998.

[5] K. Wilson, T. England and K. Van Riper, "Status of CINDER'90 Codes and Data", Los Alamos National Laboratory, LA-UR-99-361, 1999.

[6] International Commission on Radiological Protection, "Conversion Coefficients for use in Radiological Protection against External Radiation,” ICRP Publication 74, Ann. ICRP26, Pergamon Press, 1996.

[7] Title 10 Code of Federal Regulations, Part 835, "Occupational Radiation Protection", 2006.

[8] Herman Cember and Thomas Johnson, "Introduction to Health Physics," Fourth Edition, McGraw-Hill Medical, 2008.

[9] Steven Homann, "HotSpot - Health Physics Codes, Version 2.07 User's Guide", Lawrence Livermore National Laboratory, LLNL-TM-411435, 2009. 
[10] Health Physics Field Operation Procedure, "Placement and Use of Air Samplers and/or Real Time (Continuous) Air Monitors for Routine Monitoring for Airborne Radioactivity", Lawrence Livermore National Laboratory, HP-FO-04, 2006. 


\section{Table Captions}

Table I. List of major radionuclides contributing to contamination hazard, 1 day after last 20 MJ shot.

Table II. Summary of estimated contamination levels in NIF target chamber from buildup and decay from 2010 to 2012 . Values are calculated 5 days after last shot. 


\section{Figure Captions}

Fig.1. NIC ignition point design target.

Fig. 2. Dose rates due to different capsules at 1' from FW.

Fig. 3. Dose rates due to different hohlraum materials at 1' from FW.

Fig. 4. Dose rate comparison for target materials at 1' from FW.

Fig. 5. Dose rates due to noble gases outside cryo-pumps. 


\begin{tabular}{|c|c|c|c|}
\hline Ag-111 & I-131 & Np-239 & Te-131m \\
\hline Ag-113 & I-132 & Pd-112 & Te-132 \\
\hline Au-196 & I-133 & Pr-143 & U-239 \\
\hline Au-196m & I-135 & Pu-239 & Y-91 \\
\hline Au-198 & La-140 & Rh-105 & Y-93 \\
\hline Ba-140 & Mo-99 & Ru-103 & Zr-95 \\
\hline Cd-115 & Na-24 & Ru-106 & Zr-97 \\
\hline Cd-115m & Nb-95 & Sb-127 & \\
\hline Ce-143 & Nb-97 & Sr-89 & \\
\hline Ce-144 & Nd-147 & Sr-91 & \\
\hline
\end{tabular}

Table I. List of major radionuclides contributing to contamination hazard, 1 day after last $20 \mathrm{MJ}$ shot. 


\begin{tabular}{|l|c|c|c|}
\hline \multicolumn{1}{|c|}{ Year } & 2010 & 2011 & 2012 \\
\hline Gross Chamber Surface Contamination $\left(\mathrm{Bq} / \mathrm{cm}^{2}\right)$ & $1.4 \times 10^{4}$ & $3.2 \times 10^{4}$ & $1.4 \times 10^{5}$ \\
\hline Fraction of 10CFR835 Appendix D Release Criteria & $1.7 \times 10^{4}$ & $4.1 \times 10^{4}$ & $1.8 \times 10^{5}$ \\
\hline Resuspension Air Concentration $\left(\mathrm{Bq} / \mathrm{m}^{3}\right)$ & $2.3 \times 10^{2}$ & $5.2 \times 10^{2}$ & $2.3 \times 10^{3}$ \\
\hline Fraction of Airborne Concentration Limit (DAC) & $2.4 \times 10^{-2}$ & $5.3 \times 10^{-2}$ & $2.4 \times 10^{-1}$ \\
\hline Fraction of Type 3 workplace (glovebox) & $8.2 \times 10^{-7}$ & $2.5 \times 10^{-6}$ & $1.0 \times 10^{-5}$ \\
\hline DAC hours for continuous monitoring & - & - & $8.8 \times 10^{-2}$ \\
\hline
\end{tabular}

Table II. Summary of estimated contamination levels in NIF target chamber from buildup and decay from 2010 to 2012 . Values are calculated 5 days after last shot. 


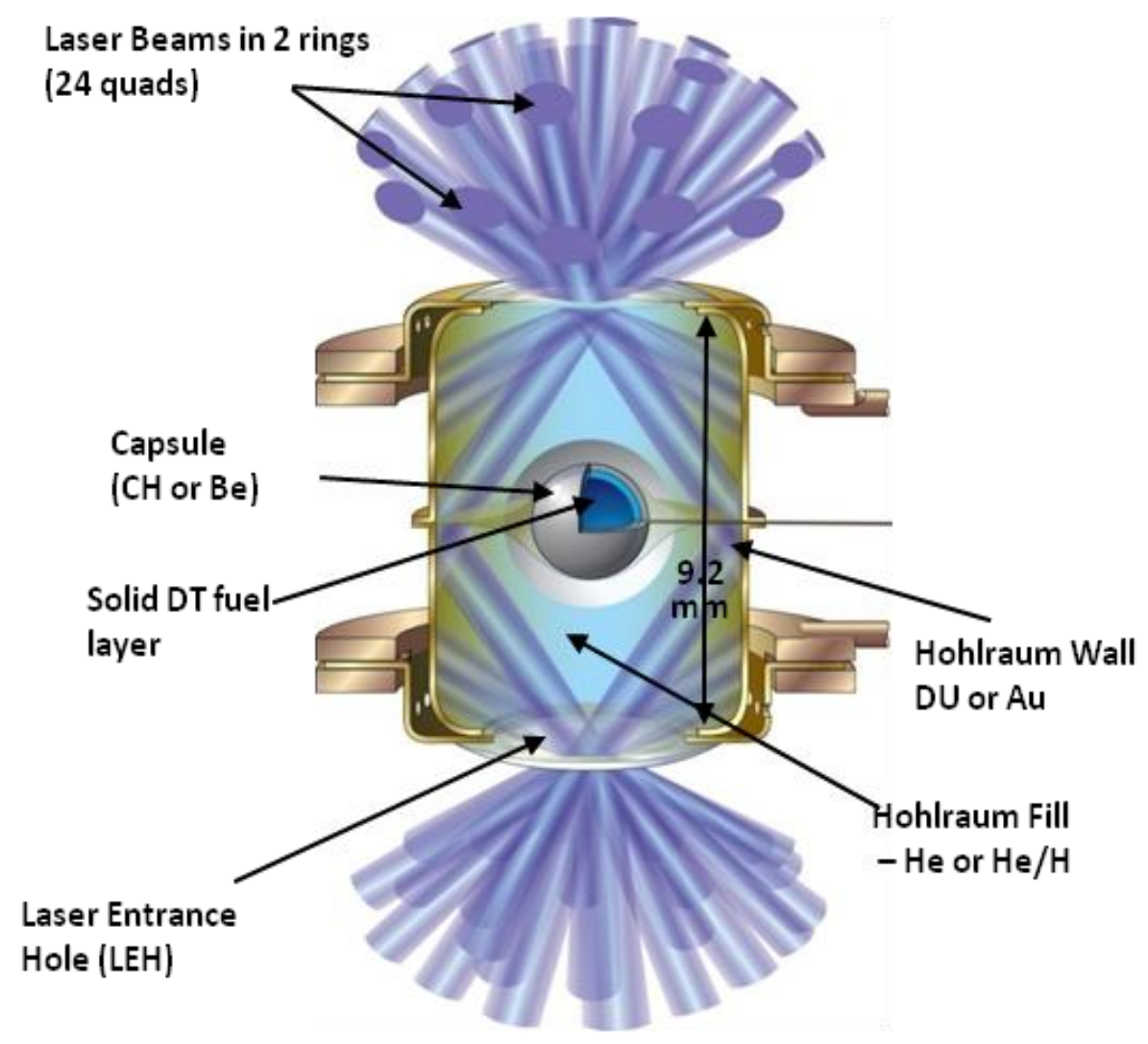

Fig.1. NIC ignition point design target. 


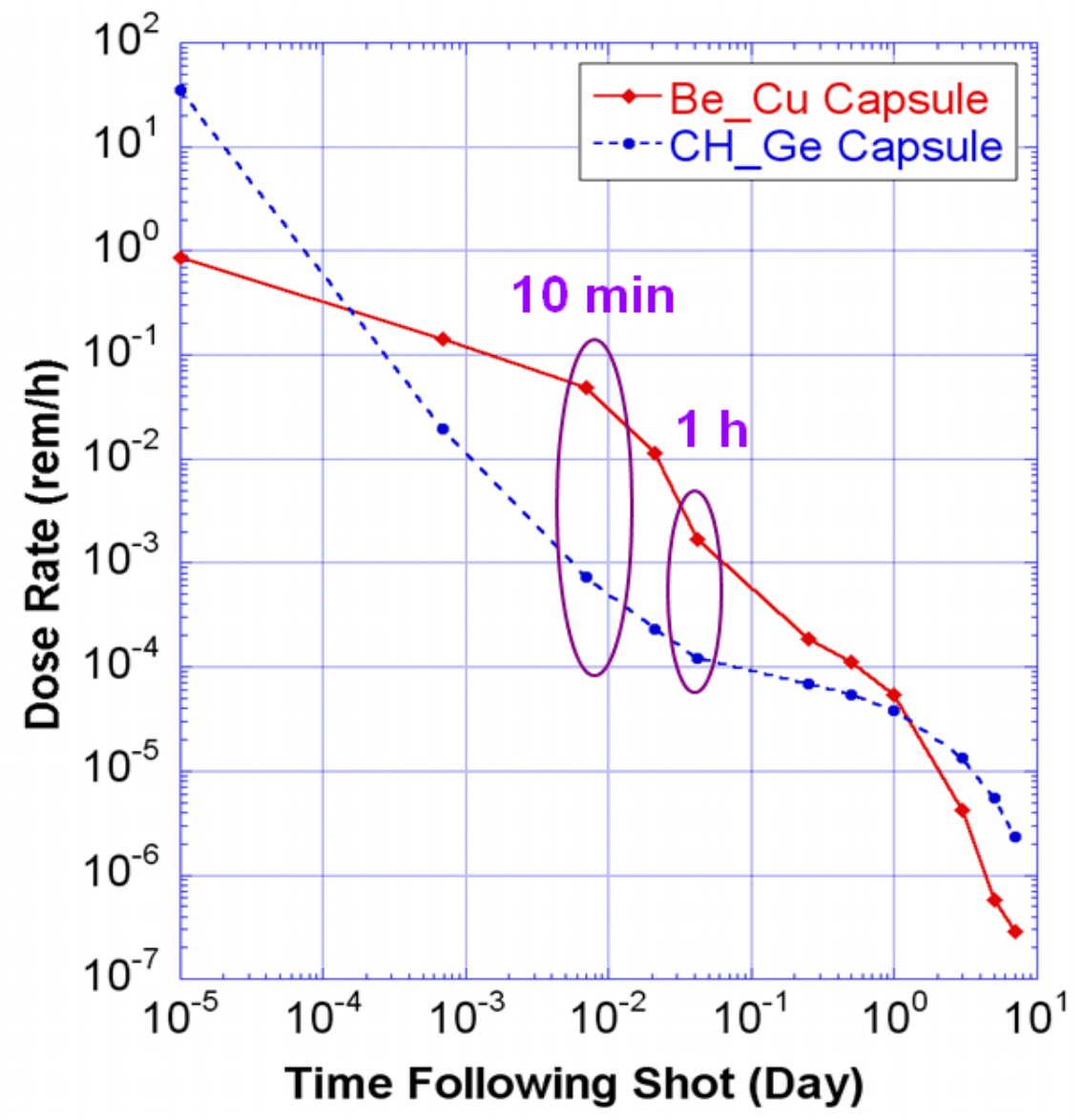

Fig. 2. Dose rates due to different capsules at 1' from FW. 


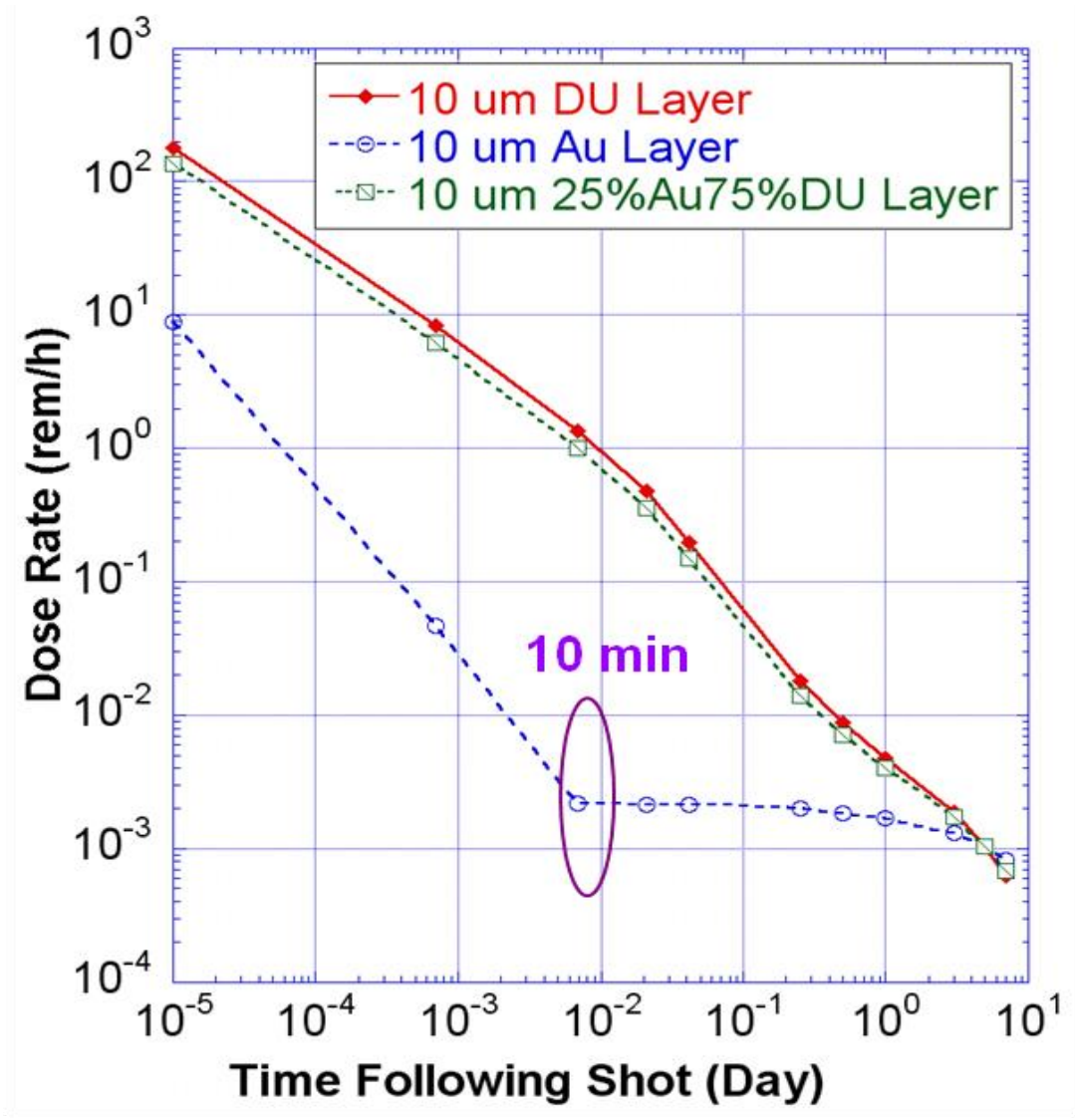

Fig. 3. Dose rates due to different hohlraum materials at 1' from FW. 


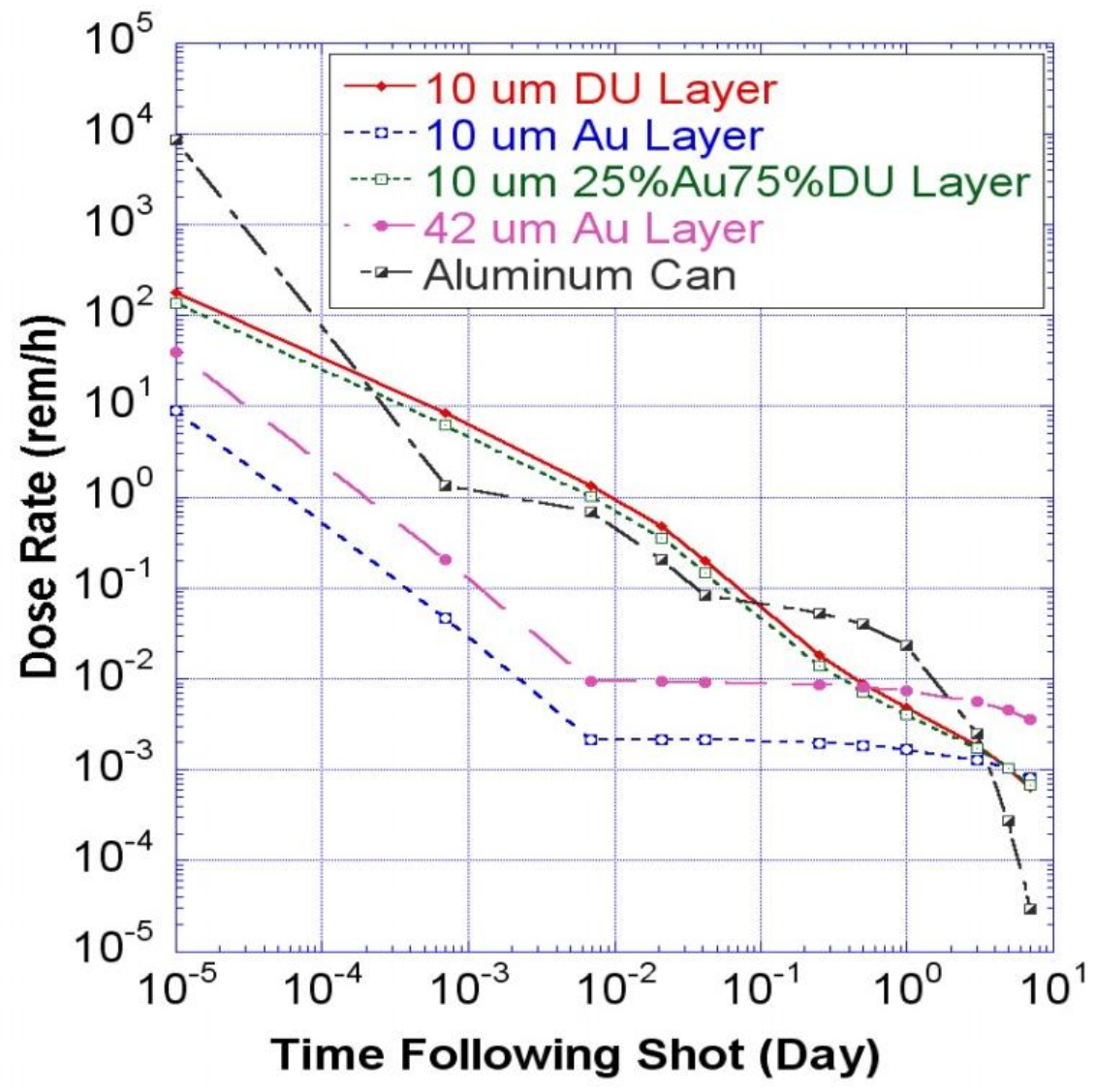

Fig. 4. Dose rate comparison for target materials at 1' from FW. 


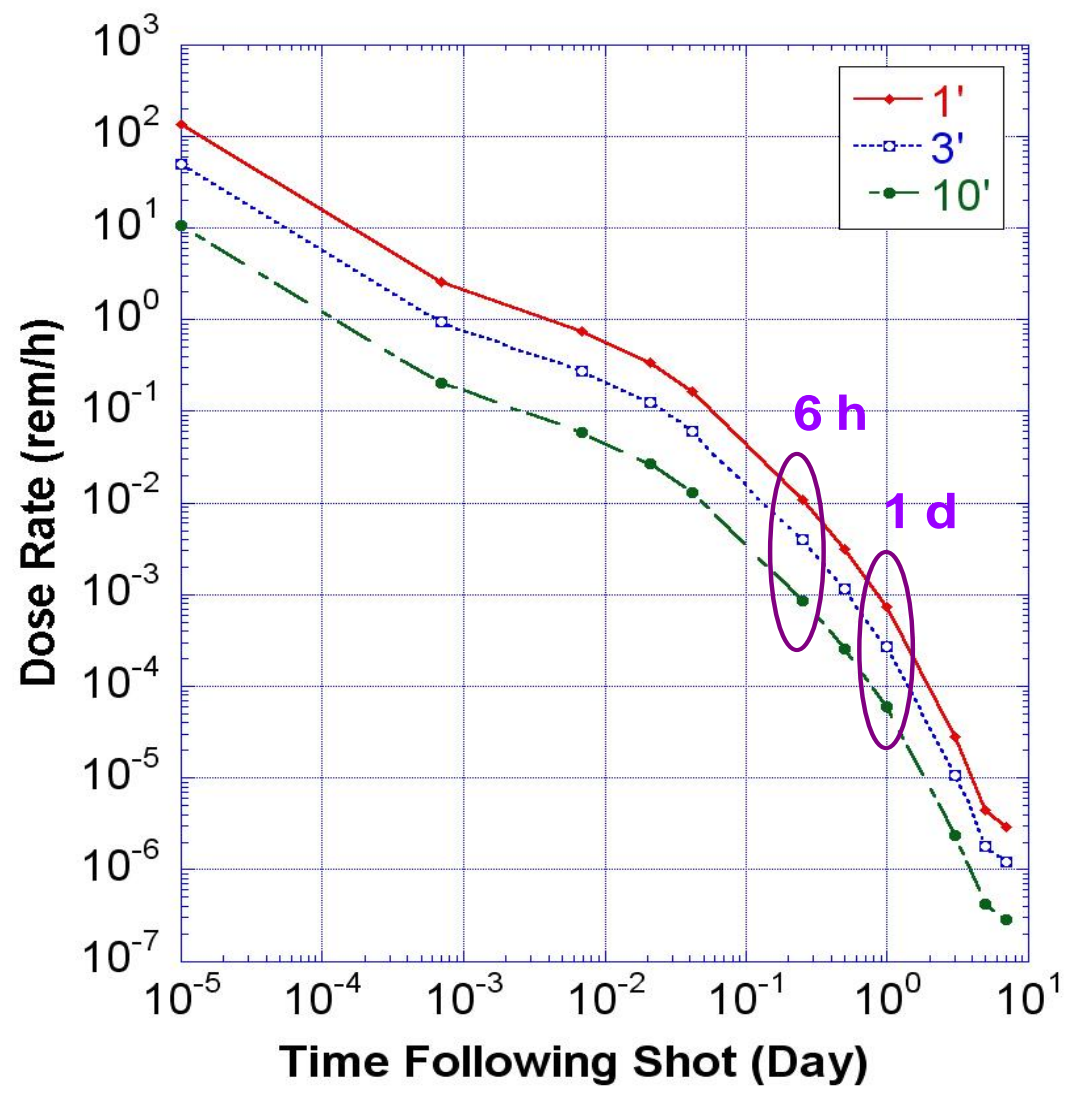

Fig. 5. Dose rates due to noble gases outside cryo-pumps. 